TABLE 1. Effect of morphine on serum LH, FSH and prolactin levels in proestrous rats

\begin{tabular}{|c|c|c|c|c|c|}
\hline Treatment & No. of rats & L. & & $\begin{array}{c}\text { FSH } \\
(\text { mean }+ \text { S.E.) (ng } m \text { mi })\end{array}$ & Prolactin \\
\hline Saline & 10 & 623 & 105 & $206.1 \ldots 37$ & $947 \quad 154$ \\
\hline Morphine & 7 & & $3^{*}$ & $110:-11$ & $144 \ldots 52^{*}$ \\
\hline
\end{tabular}

decreased LH and FSH secretion and inhibits ovulation (6), it may be that morphine inhibits ovulation by decreasing the proestrous LH and FSH surges through effects on a central dopaminergic pathway. As the increased prolactin levels in plasma may cause a stimulation of hypothalamic prolactin inhibiting factor (PIF) synthesis and/or release, which is followed by an inhibition of prolactin release (7), and acute administration of morphine to male rats increases serum prolactin levels (8), morphine may suppress the proestrous serum prolactin surge by stimulating the PIF synthesis and/or release. The possibility of a direct action of morphine on the pituitary cannot be excluded and the mechanism of morphine which inhibits the proestrous LH, FSH and prolactin surges remains to be elucidated.

Our finding suggests the possibility that morphine blocks ovulation by inhibiting the preovulatory LH surge. The role of lowered FSH and prolactin levels of morphine-treated proestrous rats in the blockade of ovulation is now being investigated.

\title{
REFERENCES
}

1) Barraclovgh, C.A. and Sawyir, C.H.: Lndocrimlogy 57, 329 (1955): 2) Blakf, C.A.: Endochinology 95, 572 (1974): 3) Me[tt.s, J, Lu, K.H., Wettke, W., Welsch, C.W., NagasaWA. H. and Quadri, S.K.: Recent Prog. Horm. Res. 28, 471 (1972): 4) Pang, C.N., Zimmermani, E. And Sawyre, C.H.: Anat. Rec. 178, 434 (1974); 5) LAl, H.: Life Sci. 17, 483 (1975); 6) Beattie, C.W., Gluckman, M.I. nni) Corbiv, A.: Proc. Soc. exp. Biol. Med. 153, 147 (1976): 7) Clemens, J.A. and Mittes, J.: Endocrinology 82, 878 (1968): 8) Collu, R., Clfrmont, M.I. and Dirhakme, I.-R.: Lurop. J. Phamacol, 37, 133 (1976)

\section{INHIBITION OF PROSTAGLANDIN SYNTHETASE SYSTEM IN THE RABBIT RENAL MEDULLA BY PSYCHOTROPIC DRUGS}

\author{
Haruo TACHIZAWA, Tadashi SAITO and Takeshi AKIMOTO \\ Research Institute, Daichi Seivatu Co., Ltd. Edogawa-ku, Tokyo 132, Japan
}

Accepted December 20, 1976

It has been reported that chlorpromazine and desipramine, a major tranquilizer and antidepressant, respectively, exert anti-inflammatory activity in animals $(1,2)$ and that chlormezanone, a minor tranquilizer, has a more potent analgesic activity than aspirin (3). Vane has proposed that the phamacodynamic activities of non-steroidal anti-in- 
Ilammatory drugs are attributable to inhibition of prostaglandin (PG) biosynthesis (4) and many workers have confirmed that non-steroidal anti-inflammatory drugs possess the ability to inhibit PG biosynthesis (5-7). Recently, certain psychotropic drugs have been shown to inhibit PG biosynthesis in vitro $(8,9)$. In the light of these results, it is of interest to consider whether the inhibition of PG biosynthesis by psychotropic drugs is related to the inti-inflammatory and analgesic activities of these agents. We investigated the inhibition of PG synthetase system in the rabbit renal medulla (rabbit PSS) using chlormezanone, hydroxyzine, diazepam, chlorpromazine and desipramine, as representatives of minor or major tranquilizers and antidepressants.

Enzymatic activity was assayed in the following incubation mixture at $37 \mathrm{C}$ for $30 \mathrm{~min}$ : $7.5 \mathrm{mg}$ of lyophilized microsomes of the rabbit renal medulla (rabbit PSS), $30,2 \mathrm{M}{ }^{3} \mathrm{H}$. arachidonic acid, $1,4 \mathrm{M}{ }^{4} \mathrm{C}$-dihomo- $\%$-linolenic acid, $1.7 \mathrm{mM}$ reduced 1 -glutathinone, $0.5 \mathrm{mM}$ l-epinephrine, $0.07 \mathrm{mM}$ EDTA-2 $\mathrm{Nit}$ and various concentrations of psychotropic drugs or reference compounds (aspirin and indomethacin) in $1.5 \mathrm{ml}$ of $0.2 \mathrm{M}$ Tris- $\mathrm{HCl}$ buffer (pH 7.5). PGs formed were extracted and separated by TLC, and the radioactivity of each spot on the TLC plate was measured by a liquid scintillation counter (10). Percent inhibition was obtained by comparing the percentage of radioactivity converted from the labeled substrates into PGs in the presence and absence of psychotropic drugs or reference compounds. IC50 values were calculated from the equation of the best fit straight lines for log concentration vs. percentage inhibition plots, and represent the molar concentration of the drugs resulting in a $50 \%$ inhibition of $P G$ biosynthesis.

As shown in Table 1. diazepam was the most potent inhibitor of psychotropic drugs tested, followed in decreasing order by chlorpromazine, hydroxyzine and desipramine. The inhibitory potencies of these drugs against PGE biosynthesis were similar to those against PGF biosynthesis. However, chlormezanone indicated no inhibition against the rabbit PSS in the concentration range from 0.1 to $3 \mathrm{mM}$. Diazepam and chlorpromazine were 11.1 and 4.9 times more potent than aspirin, respectively, with respect to their inhibition of

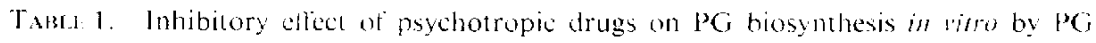
synthetase system in the rabbit renal medullat

\begin{tabular}{|c|c|c|c|c|}
\hline \multirow[t]{2}{*}{ Drugs } & \multicolumn{4}{|c|}{$\begin{array}{c}\text { Inhibition of PG formation } \\
\text { IC } 50(: \mathrm{MI}\end{array}$} \\
\hline & PGE: & $\mathrm{PG}_{2}$ & $\mathrm{PGE}_{1}$ & PGFiu \\
\hline Diazepam & $89 ! \cdot \cdot$ & 117 & 243 & 113 \\
\hline Hydroxyzine & 702 & 679 & 1000 & 735 \\
\hline Chlormezanone & inactive". & inaclive & inactixe & inactive \\
\hline Chlorpromaxine & 203 & 184 & 240 & 188 \\
\hline Desipramine & 1260 & 700 & NT: & $\mathrm{NT}$ \\
\hline Aspirin & 984 & 477 & 721 & 687 \\
\hline Indomethacin & 0.62 & 0.44 & 0.46 & 0.33 \\
\hline
\end{tabular}

a) Molar concentrations inducing a $50^{\circ}$, intribition of PG biosynthesis.

b) Values represent the means for three experiments. c) Juhibition was nil in the concentration range from 0.1 to $3 \mathrm{mM}$. d) Vot tested. 
PGE, biosynthesis. The inhibitory potencies of hydroxyzine and desipramine were of the same order as aspirin. These four psychotropic drugs were much less potent than indomethacin, a potent anti-inflammatory drug. No clcar-cut relationship was found among inhibitory potencies of minor and major tranquilizers and the antidepressant against the rabbit PSS. Since chlormczanone showed no inhibition of $\mathrm{PG}$ biosynthesis, its analgesic activity reported previously (3) maly be induced by a secondary response to suppression of the central nervous system rather than by its $P G$ synthelase inhibition. In the present study, diazepam was the most potent inhibitor of psychotropic drugs despite the lack of anti-inflammatory and analgesic activities (11). In addition, hydroxyzine which has appreciable analgesic activity but not anti-inflammatory activity (12), possessed only a weak ability to inhibit PG biosynthesis. From these results, it is conceivable that the anti-inflammatory activity shown by chlorpromazine and desipramine $(1,2)$ may be mainly induced by suppression of the central nervous system even if $P G$ synthetase inhibition by both drugs maty to some extent participate in the anti-inflammatory activity.

The inhibition of $P(3$ biosynthesis by the psychotropic drugs tested herein is apparently weak with litle relation to the anti-inflammatory and analgesic activities.

\section{RIFFRFNCES}

1) Jaqlis, R. and Ritsterer, L.: Phamacol. 6, 29 11971): 2) Marteli., F.A., Toth, E... Segre, A.D. And Corsico, N.: Furop. I. Phomacol. 2, 229(1967): 3) Takagl, K., Takayanagi, 1. AND KaYAOKa, S.: Pllamaconerrics 5. $935(1971$ ) (in Japanese): 4) VANE, J.R.: Nature Non Biol. 231, 232 (1971): 5) lakeciuchi, C. And SiH, C.J.: Prostaglandins 2, 169 (1972): 6) Flower, R.J., Chilvo, H.S. avd Cushman. D.W.: Prostaglandins 4, 325 (1973): 7) Ku. E.C., Wasvary, J.M. aND CASH. W.D.: Biochem. Pharmacol. 24, 641 (1975); 8) Lll, R.E.: Prostaglandins 5, 63 (1973): 9) KRupP, P. AND WEsP, M.: Fxperientia 31, 330 (1975): 10) Tachlzawa, H., Tsukada, W., Salio, T. Axis Akimoto, T. Japam. J. Phamacol. (in press): 1) Tsurumi, K., Hayashi, M., ABr, A., GO, K. AYd lumalira, H. : Folia phamacol. japon. 69,

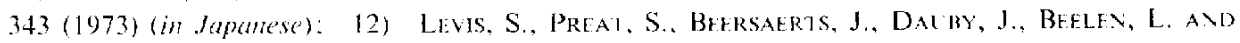
Bacciver, 1 : : frehs int. Phamacosth. Their. 109, 127 (1957)

\section{NEUROMUSCULAR BLOCKING ACTIONS OF NEUROTOXINS ISOLATED FROM LATICAUDA SEMIFASCIATA, NAJA NAJA AND NAJA NAJA ATRA A COMPARATIVE. ASSAY}

Yasushi KURAISHI, Yoshimi MISU. Hiroshi TAKAGI and Kyozo HAYASHI*

Department of Phamacology and :Department of Biological Chemistry,

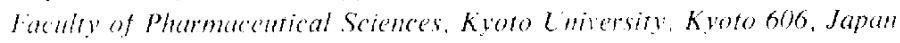

Accepted December 23. 1976

Extensive phamalological and toxicological sludies on snake venoms have revealed that the venoms of most snakes belonging to the family of Elapidae and Hydrophidac produce 